\title{
DO GESTO HESITANTE DA DOR À FUSÃO APOCALÍPTICA DO CORPO \\ LEITURA DE CRITTICA DAS LIGAÇÕES NA ERA DA TÉCNICA, ORG. DE BRAGANÇA DE MIRANDA E TERESA CRUZ
}

\author{
Helena Pires *
}

Nos anos 70 , o movimento da «body art» ou «arte corporal» reagia à figuração clássica que ora escondia o corpo, recalcando-o na expressividade do traço, ora o evidenciava, decalcando-o "na mestria gráfica dos contornos delineados» (Rosa Oliveira, 1978: 9). Entre os artistas que então procuravam perturbar a representação, encontra-se Gina Pane. Através da fotografia, a artista fixava uma verdadeira "dor de significação», o que era dado a ver em referência directa a mutilações corporais visualizadas sob a forma de cortes e de marcas, imprimidas por lâminas, agulhas e outros instrumentos de escrita sobre o corpo. O que torna esta "experiência" artística interessante é o facto de ela não visar efeitos necessariamente estéticos, mas antes a acentuação no corpo da "cumplicidade que liga a dor ao acto de conhecimento" (Rosa Oliveira, 1978: 16). Precisamente, ao lermos os textos apresentados por Bragança de Miranda e Teresa Cruz em Crítica das Ligações na Era da Técnica ${ }^{1}$, a propósito da tarefa de recensão crítica que aqui nos cumpre empreender, constatamos que estes textos parecem tomar como objecto de reflexão um corpo outro, configurado nos antípodas da acepção de Gina Pane. Um corpo que já não inscreve em si «a dor da impossibilidade de chegar à vida " ${ }^{2}$, nem a vontade de interpelar aquilo que escapa à represen-

* Universidade do Minho.

I Miranda, José A. Bragança e Cruz, Maria Teresa (Eds.) (2002). Crítica das Ligações na Era da Técnica. Publicação Porto 2001. Lisboa: Tropismos.

2 Em Fernando Pessoa (citado por Rosa Oliveira, 1978: 13) encontramos a expressão: «a dor de a arte nunca chegar à vida". 
tação, mas antes o prazer simulado da superação dos limites do próprio corpo e o desejo apocalíptico de ligação à realidade virtual. Porém, em ambos os casos, quer na "arte corporal» quer na «era da técnica», a motivação profunda que mobiliza a acção - de um lado a expressão que pretende abolir qualquer representação da realidade, do outro a técnica que promete a "hiperrealidade" e a interactividade universal - parece ser idêntica: o sonho de libertação. O nosso destino cumpre-se, assim, de formas diversas. Resta-nos escolher, por entre caminhos errantes e atópicos, a nossa forma de sobrevivência. Não será isto o que procuramos nas ligaçōes à rede?

Desenvolveremos, de seguida, algumas destas questões, adoptando a estrutura do próprio texto que temos por fim ler criticamente. Ligações estranhas, ligaçöes livres, ligações enredadas, ligações perigosas e, finalmente, ligações on-off perfazem os subtítulos que congregam, cada um deles, quatro textos, correspondentes a um mesmo número de autores ${ }^{3}$, nacionais e estrangeiros. Procuraremos, pois, «dar a ver» as ligações inter e por entre eles.

\section{Ligações estranhas $^{4}$}

A Ioucura conhece hoje o seu reduto de libertação. Camuflada sob a forma da sexualidade e da "relação entre iguais», é no on-line que ela encontra expressão, ao mesmo tempo que é reprimida pelos poderes estabelecidos. Enquanto são escondidas as marcas do crime (cf. Baudrillard, 1996), da dor e da paixão, assistimos a "uma tendência geral para uma compulsão de "ligação", que parece afectar tudo e todos» (Bragança de Miranda e Teresa Cruz: 14). É, de facto, na contemporaneidade que esta "fantasmagoria do desejo» nos toma de assalto a identidade, o corpo e a alma, num movimento de síntese, de "encontro com a imagem», de "requisição da experiência pela tecnologia" (Teresa Cruz). Toda a nossa experiência é então substituída pela força da ligação, que é como quem diz da emoção. Estranho sentimento esse que nos transporta para uma atmosfera reduzida à atracção que uma poeira no ar produz em nós, suspendendo-nos do tempo e do espaço conhecidos. Estranho devir (devir-outro) e estranha

3 Pela ordem do texto original: José Gil, Maria Teresa Cruz, Simon Penny, Laura Mulvey, José Augusto Mourāo, Hermínio Martins, Brian Massumi, Fernando José Pereira, António Machuco, Katherine Hayles, Delfim Sardo, Miguel Leal, Steven Shaviro, Maria Filomena Molder, Eduardo Prado Coelho, Bojana kunst, José A. Bragança de Miranda, Friedrich Kittler, Helder Coelho e Roc Parés.

4 Autores e respectivos textos considerados sob esta designaçāo: José Gil, "Ligação de inconscientes"; Maria Teresa Cruz, "Técnica e afeç̧ão»; Simon Penny, "Representação, actualização e ética da simulação" e Laura Mulvey, "Conexōes: um século de cinema à luz das novas tecnologias». 
captura (José Gil: 25) que nos desterritorializa para territorializar de novo, que nos desculturaliza para nos incutir uma nova cultura. Como se o que pensamos e o que sentimos, na verdade, fossem antes o pensar e o sentir de um outro através do nosso corpo (cf. Artaud, 1985: 15), o que contraria a ideia de uma originalidade, de uma fundação, de que fala Gilbert Durand (1985), ao mesmo tempo que traduz a exterioridade que se impōe a uma interioridade (Foucault, 1971). Assim acontece com a perversão sexual e psíquica. Passamos, pois, para uma experiência impressiva, penetrada pela técnica, já que «tanto a ideia de uma interioridade psíquica como a de uma fisicalidade ou corporalidade são pensadas em grande medida, como uma superfície de afecção sujeita a uma marcação ou inscrição" (Teresa Cruz: 33). Habitados pelo ciberespaço, transformamo-nos em veículos ultravelozes da cibercultura. Economizamos na nossa experiência actual e projectamo-nos num «vazio indeterminado, sem referências, num tempo "real» sem tempo, sem história, sem memória, sem direcções no espaço" (José Gil: 27). Entregamo-nos a uma completa osmose, pois longe vão os «tempos modernos» do binómio homem/máquina ou do corpo/ser. Na tecnologia digital reconhecemos secretamente um inconsciente que é, afinal, uma extensão dos nossos desejos, descobrindo que «a máquina não é um brinquedo, não é uma máquina, e não é um ser humano: é um híbrido, qualquer coisa como um cyborg» (José Gil: 28). O nosso corpo e a nossa alma são assim enformados por esse ser mágico e estranho que os toma a si, deixando-nos as amarras incómodas da carne. A nossa acção torna-se automática e reflexiva. E entre o "frenesim de sangue e tripas assumidamente adolescente» que o Quake nos oferece, ao ritmo do nosso joystick, e os "massacres ecolares de Columbine e Jonesboro», as diferenças tornam-se ténues, misturando-se a simulação com a realidade (Penny: 52). Resta-nos, assim, a experiência do desligamento, o gesto da hesitação sobre a lâmina que nos faz sentir o corpo como criação nossa (Gina Pane). Contudo, ao apercebermo-nos de que a pele deixou de ser o que separa o dentro do fora, vemos que o mundo inteiro está dentro de nós e perdemo-nos algures nos «caminhos que infinitamente se bifurcam" 5 , como se uma velocidade alucinante nos dispersasse em pedaços, desmembrados, em direç̧ão ao esfacelamento da identidade e da soberania. É a imagem desta loucura que agora vemos estranhamente estaticizada na nossa ligação com a técnica: "Enquanto o digital trouxe o estatismo à imagem em movimento, a passagem do tempo reduziu a sua ilusão de vida a uma história espectral» (Laura Mulvey: 71). Vivificados na imagem, sentimos sobretudo a ausência

5 Luis Borges, Jorge (1989). "O jardim dos caminhos que se bifurcam» in Obras Completas (Volume I). Lisboa: Editorial Teorema (490-498). 
e a morte. $\mathrm{E}$ ao contemplarmos o nosso duplo, vemos com nostalgia, no visível imediato, o não visível de nós mesmos (Régis Debray, 1994).

\section{Ligações livrè $^{6}$}

Vinculados às ligações e desvinculados das relações, julgamos assim experimentar a «liberdade» pós-moderna. De facto, o confronto real com as coisas do mundo exterior tem vindo a ser progressivamente substituído pela experiência mediada pelo computacional, construção fantasiosa e aporética, já que «à utopia da ligação livre impõe-se rapidamente a fantasmagoria da sua impossibilidade» (F. José Pereira: 119). É que se, por um lado, «a conexão ao computador oferece uma libertação em relação ao corpo e aos seus poderosos contextos sociais» (B. Massumi: 108)-porque ligados a uma comunidade global que nos distancia do «local-corpo» - por outro, a arquitectura desse mundo virtual é desenhada de forma a controlar e a vigiar panopticamente (ver M. Foucault, 2002) a nossa intimidade. Ao encarnarmos distâncias afastamos o corpo, mas impregnamo-lo, simultaneamente, de uma vitalidade trans-humana que constitui o seu aprisionamento. Suspeitamos de que agentes anónimos domesticam os movimentos do nosso corpo, registando sistematicamente cada clic e relationship-specific da performance que encetamos em direcção à satisfação da liberdade experimentada na simulação de identidades. No lugar de permanecermos em nós, para assim encontrarmos o nosso ser, no movimento imóvel e circular da doação ao outro (Cf. Mourão: 78), no lugar da «limitação recíproca» da relação, optamos pela auto-suficiência que impomos à ligação, protagonizada nas "salas de conversação". Libertamos, assim, uma vontade ilimitada de dominação. A antiga ligação erótica de que falava Platão, em $O$ Banquete, transita agora para a sexualidade, isto é, para uma «erótica generalizada». A ligação mestre-escravo mantém-se, embora transposta para os não-lugares da representação e do imaginário, os quais têm por condição o fim do "corpo" e a morte da relação. Masters of Universe, não conhecemos barreiras à satisfação do nosso prazer. Pelo contrário, deixamo-nos fundir nas múltiplas ligações totalitárias e narcisistas, e adoptamos o cyborg como nova forma de vida. Numa luta desgarrada pela sobrevivência, rendemo-nos a esta universalidade porque acreditamos que ela «não só está próxima de nós, mas estará sempre próxima de nós: a ambição de uma mutaçāo antropológica

6 Autores e respectivos textos considerados sob esta designaçāo: José Augusto Mourão, "Vínculos, novos vínculos, desvinculaçōes"; Hermínio Martins, "A singularidade está próxima»; Brian Massumi, "Exprimir a conexão: arquitectura relacional" e Fernando José Pereira; «Ligações «livres» - da construção fantasiosa à realidade doméstica». 
radical, da transição para o trans-humano, ficará sempre omnipresente na civilização tecnológica» (H. Martins: 105). Não podemos, pois, deixar de querer ser livres das memórias que nos impedem de sair, definitivamente, para fora de nós mesmos ${ }^{7}$.

\section{Ligações enredadas ${ }^{8}$}

«Embaraçada ali dentro por uma teia de vazios, eu esquecia de novo o roteiro de arrumação que traçara, e não sabia ao certo por onde começar a arrumar. $O$ quarto não tinha um ponto que se pudesse chamar de seu começo, nem um ponto que pudesse ser considerado o fim. Era de um igual que o tornava indelimitadon (Clarisse Lispector, $A$ paixäo segundo G. H., p. 36).

As práticas artísticas na rede gozam hoje de enorme investimento, em direcção a uma apaixonante aventura pela exploração de um meio cujos limites, e virtudes, restam ainda por descobrir. Tal como diz Miguel Leal, fazendo uso da metáfora da pirataria, «para os artistas, o apelo mágico dos tecnomundos cibernéticos é originário do mesmo sentimento: navio e ilha, clausura e libertação" (185). A ausência de um "aqui e agora»-outrora marca da existência única e da autenticidade da obra de arte - que, nas palavras de Walter Benjamin (1992), caracteriza a era da reprodutibilidade técnica, é a principal condição que esta nova forma de arte encontra no meio cibernético. Até porque, neste caso, o ponto onde a obra começa e o ponto onde ela acaba são indetermináveis, se pensarmos que o comportamento real de uma máquina, como refere António Machuco Rosa, pode escapar às especificações previamente introduzidas pelo designer, contrariando o ideal das arquitecturas clássicas de controlo. Katherine Hayles chega mesmo a colocar a questão de as indicações no ecrã deixarem de ser textos efectivamente legíveis: «O texto anuncia a sua diferença em relação ao corpo humano através desta ilegibilidade, lembrando-nos de que o computador também é um escritor e, mais ainda, um escritor cujas operações não podemos inteiramente compreender na sua complexidade semiótica» (159). Inscrita numa espécie de «não-lugar», na medida em que são

7 Referimos, a este propósito, dois textos fundadores: L'anti-Oedipe, de Gilles Deleuze e Félix Guattari (1972), que apresenta desde logo a questāo da ligaçāo em termos de corpo, máquina e desejo; e Understanding Media, de Marshall McLuhan (1964), que trata da ligaçāo técnica-estética.

8 Autores e respectivos textos considerados sob esta designaçāo: António Machuco, "Dos mecanismos clássicos de controlo às redes complexas»; Katherine Hayles, "Redes metafóricas em Lexia to Perplexia"; Delfim Sardo, "Conexões low-tech e performatividade» e Miguel Leal, «Madagáscar [aventura e catatonia]: uma reflexāo sobre as práticas artísticas na rede». 
desconhecidos o princípio da criação do webdesign e a originalidade do seu autor (ver G. Durand, 1979), bem como a real identidade do agente utilizador e o fim desse "espaço intersticial" ${ }^{9}$, a prática das artes visuais na rede digital procura ainda, permanentemente, ultrapassar os limites da impossibilidade de representar a continuidade do "movimento enquanto ele mesmo» (Sardo: 172). Pelo contrário, esta "nova forma de arte» e a linguagem digital em geral parecem evidenciar a estaticidade da imagem, o seu fim, a sua morte (ver R. Debray, 1994). Ela já não representa, não tem por vocação dar a ver, nem é o sentido construído em e pela relação, como bem defendem, respectivamente, André Joly (1982) e Francis Jacques (1987). Antes, deriva algures entre uma presença e uma ausência dispensando-se de reclamar a si qualquer compromisso de inscrição ética com o outro.

Recorrendo novamente à analogia com o mundo da pirataria, é como se, uma vez entregues à aventura sem retorno do ciberespaço, abandonássemos todas as amarras que nos ligam à nossa história e adoptássemos em sua substituição um único princípio de orientação: o reconhecimento e obediência cega ao poder do mais forte. No navio, àquele que pela sua implacável crueldade, destemor e capacidade de amedrontar os demais, assim se impõe (pelo menos até ao momento em que as suas «qualidades» forem superadas por outro skipper ainda mais feroz). Na rede - pela possibilidade ilimitada que nos dá de incorporarmos uma identidade escolhida -, à imagem. Sem os filtros da razão e da argumentação, sem os limites dos afectos inscritos na relação com o outro, deixámo-nos enredar pela emoção que a imagem provoca em nós e exilamo-nos numa ilha perdida e desconhecida, esquecendo para sempre o porto de onde partimos.

\section{Ligações perigosas ${ }^{10}$}

Em A arma impossivel, de Philip K. Dick, os humanos inventam uma arma capaz de liquidar os extra-terrestres que ameaçam a terra. Esta consiste num jogo de computador, cujo poderoso efeito é o de sugar os seus utilizadores, irreversivelmente, para dentro do ecrã. É com esse propósito que o jogo é oferecido aos indesejados visitantes que assim acabam definitivamente apanhados, ao virem a fazer parte, eles próprios, do jogo. Este

9 Ver "corpo intersticial" in Dinis Guarda (Ed.) (2002). Corpo Fast Forward. Publicação Porto 2001. Lisboa: Ópio.

10 Autores e respectivos textos considerados sob esta designaçāo: Steven Shaviro, «Ligações perigosas: a ontologia das redes digitais»; Maria Filomena Molder, "Apologia da inadaptação»; Eduardo Prado Coelho, "Estruturas e redes» e Bojana Kunst, "Quero partilhar-te que me fazes? Aterrado e imóvel: o corpo íntimo». 
perigo de arrastamento parece ser também imanente à nossa ligação à Internet. Como descreve Steven Shaviro, através da distraç̧äo, «a Net solicita todo o meu corpo. Tenho de me sentar bem direito, mesmo à frente do ecrã, sem me desaprumar, com os braços horizontais e as mãos ocupadas. Tenho também de me manter muito mais perto do ecrã do que alguma vez é o caso com a TV (...) Entretanto, os meus dedos percorrem o teclado... a mão torna-se uma extensão do meu olho: meto-a directamente no ecrã» (200-201). De facto, é como se todo o dispositivo procurasse controlar-nos, antes de mais, sujeitando o nosso próprio corpo. Como se o próprio corpo fosse «investido das relaçōes de poder» (Michel Foucault, 2002: 24). Ao contrário de um «olho panóptico», que vigia sem ser fitado, «num mundo totalmente em rede, onde cada ponto comunica directamente com cada ponto, o poder já não é sem rosto e invisível. Pelo contrário, opera à vista de todos" (Steven Shaviro: 207). Trata-se agora de uma vigilância que está em todo o lado e de um poder absoluto porque acentrado. A propósito da mutação de estruturas centradas para estruturas acentradas, Eduardo Prado Coelho (240) destaca as suas implicações profundas em termos de espaço (do extensivo para o intensivo) e em termos de tempo (do articulado para o movimento perpétuo).

No lugar da representação que tendia a fazer-se passar pela realidade, de que falava Guy Debord, em A sociedade do espectáculo, ou de a representação realizar o mundo como signo, como assinala Jean Baudrillard (1979), a simulação apresenta-se com uma eficácia incomparavelmente maior na aniquilação da nossa individualidade. É que não há sequer existência prévia à rede. Não há simplesmente nada a esconder. Inversamente ao que defendia Heidegger, ao falar da técnica como um modo de verdade e de desvelamento (1958: 18), a rede digital não remete para um mundo natural nem para o ideal moderno do desenvolvimento ${ }^{11}$. Antes para «uma espécie de duplo da realidade empírica» (Jean Petitot citado por Maria Filomena Molder: 222), uma realidade virtual, mais perfeita e sedutora do que a real, enfim uma réplica do "mundo que há». Ou seja, "o perigo está na substituição ignara da experiência viva por um conceito vazio e que se torna tanto mais potente quanto mais vazio" (Maria Filomena Molder: 229) porque nos suga a interioridade e a "visão do retorno", revelando-nos a eternidade do êxtase programado, previsível, e transformando-nos em sujeitos que obedientemente respondem a estímulos ${ }^{12}$. Mas este perigo pode ainda conter em si a

11 No seu ensaio sobre a técnica já Walter Benjamin (1992) falava peremptoriamente de a técnica deixar de ser meramente instrumental.

12 A perigosidade desta revolução tecnológica é figurada em Moisés Martins (2002: 189) através de uma dupla imagem: por um lado, a imagem de «uma absurda insulação disciplinar (com a electrónica a projectar a ilha que nos permite lançar no mar ciberespacial inúteis 
nossa salvação. É que o nosso encontro com a máquina pode, simultaneamente, combater um outro perigo ainda maior: o da separação radical entre o humano e o in-humano, isto é, o perigo da "purificação», próprio do pensamento moderno, que toma o corpo como um «lugar de não-vida, um simples objecto do interesse científico e da representação" (Bojana Kunst: 248). Ao nos darmos conta, perante a realidade virtual, de que já não conseguimos distinguir o "humano petrificado da estátua animada», uma vez que vemos na máquina uma extensão de nós mesmos ${ }^{13}$, dá-se em nós a abertura ao desconhecido, quem sabe o caminho em direcção ao outro.

\section{Ligações on/off ${ }^{14}$}

Feita de ligaçōes e de desligações, «a experiência deve ser considerada como um continuum de fragmentos, dispersões, pedaços, cuja união tem algo de enigmático» (Bragança de Miranda: 259). Estar on-line apresenta-se hoje como a garantia mais forte de participação numa experiência comum, que nos enreda a todos, e a estratégia mais eficaz na configuração da nossa identidade. Embora o princípio da linguagem digital se reduza a uma alternância entre zeros e uns, isto é entre o Nada e o Uno, como salienta Friedrich Kittler (281), ligarmo-nos ou desligarmo-nos da rede não é o mesmo que pressionar o botão on/off de um computador. $\mathrm{Na}$ verdade, assistimos hoje à «(im)possibilidade do (des)ligar», uma vez que o poder, a autonomia e a mobilidade delegados nos agentes informáticos são uma consequência inevitável da distribuição e descentralizaçāo dos procedimentos tecnológicos (Helder Coelho: 299-300). Tomemos o exemplo dado por Helder Coelho: "o vírus não se desliga, mata-se» (300). Mas não é com tal facilidade que podemos falar da morte da ligação com o sistema. Como refere Roc Parés, a extensão entre o utilizador (cérebro/olhos/mão) e o sistema (ecrä/rato/cursor) é evidente (304). Derrick de Kerchove fala de um «eu expandido", assim encerrando o seu texto intitulado A pele da cultura: "Esta é uma nova experiência psicológica com implicações imensas. A melhor

mensagens dentro de garrafas)"; e por outro lado, a imagem de «um mundo comunicacional que é um ruido vazio (com a interactividade a cercar compulsiva e inexoravelmente toda a ilha, tal um mar virtual coalhado de garrafas com absurdas mensagens dentro delas)".

13 Em A pele da cultura, KercKhove descreve bem como "os media electrónicos são extensōes, nāo só do sistema nervoso e do corpo mas também da psicologia humana» (22). Refirase, a este propósito, a título de ilustraçāo, o filme Blade Runner, de Ridley Scott, baseado no romance homónimo de P. K. Dick.

14 Autores e respectivos textos considerados sob esta designação: José A. Bragança de Miranda, "Para uma crítica das ligaçōes técnicas»; Friedrich Kittler, "Ligações on-off»; Helder Coelho, «A atracçāo irresistível pela complexidade» e Roc Parés, "Etologia de Z». 
vingança contra as psicotecnologias que nos transformariam em extensões delas próprias é incluí-las na nossa psicologia individual. Um novo ser humano está a nascer» (284).

Depois da crise da «identidade», levada pelo pós-modernismo às últimas consequências, as tensões da (des)ligação são as da divisão que ameaçam o Uno que compulsiva e inconscientemente procurámos. Ligaçöes pontuais, efémeras, imprevisíveis ou perversas alimentam a "fantasmagoria dos nossos desejos», seduzindo-nos através de uma "erótica generalizada» feita de imagens que governam indivíduos «livres».

\section{Em conclusão}

Podemos dizer que Crítica das Ligações na Era da Técnica apresenta-se como um contributo fundamental para a compreensão do actual novo ser. Um ser estranho porque rendido à loucura psicótica da atracção e à morte da experiência, ao mesmo tempo que goza uma ilusão de vida na sua ligação à realidade virtual. Um ser livre porque liberto da relação e da carne, finalmente entregue à realização de uma utopia, embora escravo dos Masters of Universe que definem, por si e para si uma identidade simulada e universal. Um ser enredado porque lançado à deriva numa teia de vazios, cujo princípio e fim são indelimitados. Um ser perigoso porque exímio na obediência a estímulos capazes de o fazerem substituir a realidade empírica por uma réplica, moldada ao sabor dos seus caprichos. Um ser on/off porque expandido para fora de si mesmo, ligado a um novo sistema que o obriga a repensar a (des)ligação sentida com a identidade perseguida. Enquanto desafios ao (pre)conhecimento de nós mesmos, tais ligações, na presente era da técnica, mostram, ainda, na sua desumanização, a possibilidade de, pela experimentação do não-ser, reencontrarmos, quem sabe, a emoção perdida do nosso existir.

\section{REFERÊNCIAS BIBLIOGRÁFICAS:}

ARTaud, Antonin (1985). Os tarahumaras. Lisboa: Relógio d'Água.

BAUDRILLARD, Jean (1978). Simulacres et simulation. Paris: Galilée.

BAUDRILLARD, Jean (1996). O crime perfeito. Lisboa: Relógio d'Água. (Original em francês publicado em 1995.)

BENJAMIN, Walter (1992). Sobre arte, técnica, linguagem e política. Lisboa: Antropos. (Original em alemão publicado em 1936.)

DEBORD, Guy (1992). La société du spectacle. Paris: Gallimard. (Original publicado em 1967.) 
DEBRAY, Régis (1994). Vida y muerte de la imagen. Historia de la mirada en Occidente. Barcelona: Ediciones Paidos. (Original em francês publicado em 1992.)

Deleuze, Gilles e Guattari, Félix (1972). l'anti-Oedipe. Paris: Éditions de Minuit.

DURAND, Gilbert (1985). Limagination symbolique. Paris: PUF.

Foucault, Michel (1971). L'ordre du discours. Paris: Gallimard.

Foucault, Michel (2002). Vigiar e punir. Petropolis: Vozes. (Original em francês publicado em 1975.)

Guarda, Dinis (Ed.) (2002). Corpo Fast Fonward. Publicação Porto 2001. Lisboa: Ópio.

HeIdegger, Martin (1958). «La question de la technique» in Essais et conférences. Paris: Gallimard. (Original en alemāo publicado em 1954.)

Jacques, Francis (1987), „De la signifiance» in Revue de Métaphysique et de Morale. N. 2 (179217).

JoLx, André (1982). "Pour une théorie générale de la signifiance» in N. Mouloud e J. M. Vienne (Org.). Langages, connaissance et pratique. Lille: Université de Lille III (103-125).

KeRcKhove, Derrick de (1997). A pele da cultura. Lisboa: Relógio d'Água. (Original em inglês, publicado em 1995.)

Lispector, Clarisse (2000). A Paixāo segundo G. H. Lisboa: Relógio D'Água.

McLuhaN, Marshall (1964). Understanding Media. Nova Iorque: Mc Graw-Hill.

MARTINS, Moisés de Lemos (2002). A linguagem, a verdade e o poder - Ensaio de semiótica social. Lisboa: Fundaçāo Calouste Gulbenkian.

Rosa Oliveira, Emidio (1978). "Gina Pane ou o corpo alusivo da dor" in Colóquio Artes, n. 39, 2." série. Lisboa: Fundação Calouste Gulbenkian (9-17). 